\title{
PENERAPAN PENGEMBANGAN TEORI TECHNOLOGY ACCEPTANCE MODEL (TAM) DAN MOTIVASI TERHADAP INTENSI MAHASISWA DI JAKARTA UNTUK MENGGUNAKAN TABLET
}

\author{
Hadi Nugroho, Usep Suhud, Rochyati \\ Fakultas Ekonomi, Universitas Negeri Jakarta \\ hadingrho@gmail.com,usuhud@unj.ac.id,rohyati@unj.ac.id
}

\begin{abstract}
ABSTRAK
Penelitian ini bertujuan untuk menguji model penelitian yang dibangun berdasarkan teori-teori yang ada, dengan pertimbangan apakah model yang diajukan dapat diterapkan/di implementasikan pada penelitian-penelitian selanjutnya. Jumlah sampel dalam penelitian ini adalah 202 responden. Kemudian Teknik pengambilan sampel yang digunakan adalah teknik purposive sampling dan teknik pengumpulan data dengan skala Likert 6 skor/point. Data di analisis menggunakan exploratory menggunakan SPSS v23 dan confirmatory factors analysis menggunakan Amos v22. Empat dari lima hipotesis yang diajukan diterima dan selebihnya ditolak, $\mathrm{H}_{2}$ ditolak yang berarti menyimpulkan bahwa mahasiswa di Jakarta setelah memiliki persepsi kemudahan yang positif tidak langsung berdampak terhadap sikap yang possitif pula, melainkan mempengaruhi persepsi manfaat terlebih dahulu baru berdampak pada sikap dari pada peggunaan. Dan berikut hasil hipotesis, $\mathrm{H}_{1}$ memiliki nilai critical ratio 5,533 yang berarti hipotesis diterima. $\mathrm{H}_{2}$ ditolak dikarenakan skor critical ratio -,371 berarti $<1,96$. Selanjutnya, $\mathrm{H}_{3}$ memiliki nilai critical ratio 1,965 yang berarti hipotesis diterima. Kemudian $\mathrm{H}_{4}$ diterima dengan skor critical ratio 2,070 dan $\mathrm{H}_{5}$ diterima dengan skor 2,142 yaitu >1,96.
\end{abstract}

Kata Kunci : technology acceptance model,persepsi kemudahaan penggunaan, persepsi manfaat, sikap, motivasi, intensi menggunakan, tablet, mahasiswa, Jakarta 


\section{PENDAHULUAN}

Seperti yang diketahui dengan menggunakan gadget, akan dapat memberikan kemudahan dan manfaat lebih bagi penggunanya. Salah satu khalayak yang paling banyak dalam penggunaan terhadap gadget adalah mahasiswa/i, dikarenakan penggunan Internet di Indonesia Mayoritas Usia 18-25 Tahun. Survei APJII (asosiasi penyelenggara jasa internet Indonesia) dan Puskakom UI ini juga mengungkap bahwa mayoritas pengguna internet di Indonesia terhadap tablet sebesar 13 persen. mereka memanfaatkan fungsi dari gadget tersebut untuk membantu proses belajar sampai dengan tugas-tugas perkuliahan.

Selain memiliki manfaat dan kemudahan dalam penggunaan, diantaranya menganggap apabila menggunakan gadget dengan merk tertentu dengan kualitas dan material bahan yang tinggi, akan dapat meningkatkan strata sosial mereka. Hal tersebut merupakan salah satu faktor seseorang untuk menimbulkan intensi dalam menggunakan gadget.

Namun dengan keberagaman manfaat yang diberikan oleh tablet, tidak jarang masih terdapat orang-orang yang enggan atau tidak tertarik untuk menggunakan gadget tersebut. Sebagai informasi, penjualan iPad hingga saat ini dilaporkan terus menurun dimana faktor pengguna yang lebih jarang mengganti tablet dibanding smartphone berperan cukup penting. Pada kuarter kemarin, Apple melaporkan sebesar 13\% penurunan penjualan iPad ke angka 10.9juta unit yang berarti turun 18\% dibandingkan tahun sebelumnya. Analis percaya bahwa tahun 2018 pasar bisnis akan memiliki hingga $20 \%$ dari pangsa pasar tablet secara keseluruhan.

Penurunan minat terhadap penggunaan tablet juga terlihat di Indonesia, karena sejak akhir 2015 lalu, penjualan gadget tablet sudah mulai lesu ditandai dengan penurunan angka penjualan. Menurut perusahaan riset International Data Corporation (IDC) di akhir Oktober 2015 lalu, pengapalan tablet pada kuartal III (Q3) 2015 turun 12,6 persen dibandingkan periode yang sama tahun lalu. Total pengapalan tablet pada Q3 2015 mencapai 48,7 juta unit. Akhirnya, di kuartal akhir tahun 2015, dari lima besar vendor tablet, tiga di antaranya mengalami penurunan pangsa pasar. Berdasarkan data yang dirilis IDC, meskipun masih di peringkat satu, pasar Apple iPad turun 19,7 persen, lalu di posisi kedua Samsung, pangsa pasar merosot 17,1 persen dan Asus 43,4 persen. Sedangkan Lenovo yang berada di posisi tiga stagnan dengan 0,9 persen pangsa pasar,

Pada penelitian ini, peneliti menerapkan teori Technology Acceptance Model (TAM) sebagai kerangka model penelitian dan juga dikembangkan terhadap intensi mahasiswa untuk menggunakan tablet, yang di dalam nya terdapat lima konstruksi utama yaitu, Perceived usefulness, Perceived ease of use, Attitude toward using, Intention to use dan Actual use. Penelitian ini juga bertujuan untuk menguji atau menerapkan kerangka model yang di bangun berdasarkan teori-teori yang ada. 
Untuk dapat menimbulkan intensi menggunakan, Faktor pertama yang mempengaruhi intensi untuk menggunakan adalah sikap. Berdasarkan penelitian yang dilakukan oleh Khancanatanee, Suwanno, dan Jarernvongrayab (2014) di Thailand. Hasil yang sama juga dilakukan pada penelitian yang dilakukan oleh O'regan, Chang (2015) di China.

Faktor kedua yang mempengaruhi intensi untuk menggunakan adalah motivasi. Berdasarkan penelitian yang dilakukan oleh Kim, Kim dan Wachter (2013) di Eastern University U.S.A mengenai pengaruh motivasi terhadap mobile engagement intention. Penelitian tersebut menyatakan bahwa motivasi mempunyai pengaruh positif dan signifikan terhadap mobile engagement intention. Penelitian yang serupa juga dilakukan oleh Omigie, Zo dan Rho, (2015) di Nigeria.

Faktor ketiga yang mempengruhi intensi untuk menggunakan adalah pengaruh sosial. Berdasarkan penelitian yang dilakukan oleh Raman dan Krishnasamy (2015) di Malaysia. Penelitian tersebut menyatakan bahwa faktor sosial berpengaruh positif dan signifikan terhadap intensi untuk menggunakan. Penelitian yang sama juga dilakukan oleh Gayar, Moran dan Hawkes (2011) di Midwestern Institution, mengenai penerimaan penggunaan tablet terhadap pelajar di Midwestern Institution.

Faktor kelima yang mempengaruhi intensi untuk menggunakan adalah persepsi kesesuaian. Berdasarkan penelitian yang diteliti oleh Kanchanatanee, Suwanno dan Jarenvongrayeb (2014) di Thailand, Menyatakan bahwa persepsi kesesuaian berpengaruh positif dan signifikan terhadap intensi menggunakan $e$-marketing.

Setelah menetapkan faktor yang mempengaruhi intensi menggunakan, secara tidak langsung faktor sikap ternyata juga dipengaruhi oleh beberapa faktor-faktor. Faktor keenam yaitu sikap dipengaruhi oleh persepsi manfaat, berdasarkan penelitian yang dilakukan oleh Praveena dan Thomas. (2014) di Kerala, India. Mengenai faktor-faktor yang mempengaruhi sikap dan intensi untuk menggunakan facebook. Peneliti menyatakan bahwa persepsi manfaat berpengaruh positif dan signifikan terhadap sikap. Penelitian yang sama juga dilakukan oleh Khanh dan Gim (2014) di Vietnam.

Faktor keempat yang mempengaruhi intensi menggunakan adalah harapan kinerja. Berdasarkan Nawaz dan Thelijjagoda (2015) di Sri lanka, mengenai minat warga Sri lanka menggunakan e-Government. Penelitian tersebut menyatakan bahwa harapan kinerja berpengaruh positif dan signifikan terhadap intensi untuk menggunakan e-Government.

Faktor ketujuh yaitu sikap dipengaruhi oleh persepsi kemudahan penggunaan. Berdasarkan penelitian yang dilakukan oleh Juniwati (2014) di kalimantan, Indonesia. Mengenai faktor yang mempengaruhi intensi untuk berjualan online, menyatakan bahwa persepsi kemudahan penggunaan berpengaruh positif dan signifikan terhadap sikap. Kemudian penelitian yang sama juga dilakukan oleh Praveena dan Thomas (2014) di Kerala, India. 
Dan faktor terakhir yang secara tidak langsung mempengaruhi intensi berdasarkan penelitian yang dilakukan oleh Kim (2013) di Korea, mengenai studi penggunaan smartphone di Korea. Peneliti menyatakan bahwa persepsi kemudahan penggunaan berpengaruh positif dan signifikan terhadap persepsi manfaat. Penelitian yang sama juga dilakukan oleh Park (2009) di Korea, mengenai analisis TAM terhadap intensi mahasiswa untuk menggunakan e-learning. Dari penelitian di paragraf ini menyatakan bahwa sebelum mempengaruhi sikap, persepsi manfaat di pengaruhi oleh persepsi kemudahan penggunan.

Berdasarkan hasil wanwancara terhadap 50 mahasiswa yang ada di Jakarta, kebanyakan dari mereka belum mempunyai tablet, dari 50 hasil wawancara hanya 14 yang memiliki tablet dan menggunakannya, sisanya sebanyak 36 mahasiswa tidak memiliki tablet.

Dari 36 mahasiswa yang tidak memiliki tablet, 12 mahasiswa memiliki intensi untuk menggunakan teblet dalam beberapa waktu kedepan, dan sisanya sebanyak 24 tidak mempunyai intensi untuk menggunakan tablet.

Rendahnya intensi mahasiswa terhadap penggunaan tablet dipengaruhi berbagai macam faktor. Faktor yang paling dominan mempengaruhi rendahnya intensi mahasiswa terhadap penggunaan tablet adalah persepsi kemudahaan penggunaan, dari hasil wawancara mereka merasa sulit untuk mengoperasikan tablet ketimbang smartphone dan juga ukuran tablet yang terlalu besar.

Berdasarkan hasil data, fakta dan wawancara di atas yang bersumber dari artikel, penelitian sebelumnya, dan responden, peneliti bertujuan meneliti apakah faktor-faktor tersebut akan berpengaruh positif terhadap intensi mahasiswa untuk menggunakan tablet.

\section{TINJAUAN PUSTAKA}

Berdasarkan latar belakang masalah diatas yang bersumber dari beberapa penelitian sebelumnya, maka dapat dikemukakan hal-hal yang mempengaruhi rendahnya intensi penggunaan tablet adalah sebagai berikut:

1. Rendahnya sikap dalam menggunakan tablet.

2. Rendahnya motivasi dalam menggunakan tablet.

3. Buruknya faktor sosial yang mempengaruhi penggunaaan tablet.

4. Rendahnya harapan kinerja dalam menggunakan tablet.

5. Buruknya persepsi kesesuaian dalam menggunakan tablet.

6. Buruknya persepsi manfaat dalam menggunakan tablet.

7. Buruknya persepsi kemudahan penggunaan dalam menggunakan tablet.

8. Persepsi kemudahan penggunaan berpengaruh terhadap persepsi manfaat. 


\section{Model Penelitian}

Penelitian ini adalah penelitian pengembangan yang menerapkan teori Technology Aceeptance Model (TAM) terhadap intensi seseorang untuk menggunakan sistem tertentu. Berdasarkan penelitian-penelitian sebelumnya banyak peneliti ahli yang menerapkan teori TAM untuk menjelaskan sebuah penerimaan teknologi. TAM di adopsi untuk menjelaskan tingkat kesediaan pengguna untuk menggunakan teknologi informasi, Davis, Bagozzi dan Warshaw mengusulkan TAM menjelaskan intensi untuk menerima sistem komputer, berdasarkan teori sikap psikologi. TAM mempunyai lima konstruksi utama yaitu:

1. Perceived Usefulness (persepsi manfaat): "The degree to which a users believes that his/her work performance can be improved by using a certain system", (sejauh mana pengguna yakin bahwa / kinerja nya dapat ditingkatkan dengan menggunakan sistem tertentu).

2. Perceived Ease Of Use (persepsi kemudahan penggunaan): "The degree to which a users believes that physical or mental effort is not required when using a certain system", (Tingkat dimana pengguna percaya bahwa upaya fisik atau mental tidak diperlukan bila menggunakan sistem tertentu).

3. Attitude Toward Using (sikap terhadap penggunaan): “is a person's enduring evaluation of his or her feelings about and behavioral tendencies toward an object or idea", (Titik pandang seseorang dalam mengevaluasi sebuah objek atau ide tertentu).

4. Intention to Use (intensi menggunakan): "It used to measure the degree of users intention to carry ou certain behavior", (intensi adalah ukuran dari kekuatan intensi seseorang untuk melakukan perilaku tertentu dimasa depan).

5. Actual Use (penggunaan aktual): "Drafted in the measurement of the frequency and duration of use of the system that lead to user satisfaction", (Dikonsepkan dalam pengukuran suatu frekuensi dan durasi waktu penggunaan sistem yang berujung terhadap kepuasan pengguna).

Namun dalam penelitian ini, peneliti melakukan sebuah pengembangan dan pembatasan dalam penerapan teori TAM, dengan menambahkan motivasi sebagai variabel independen yang mempengaruhi Intensi sebagai variabel dependen, kemudian membatasi teori menjadi persepsi manfaat, persepsi kemudahan penggunaan, sikap dan intensi. 
Gambar 1.

Variabel X1, X2, Y1, Y2 dan variabel Z

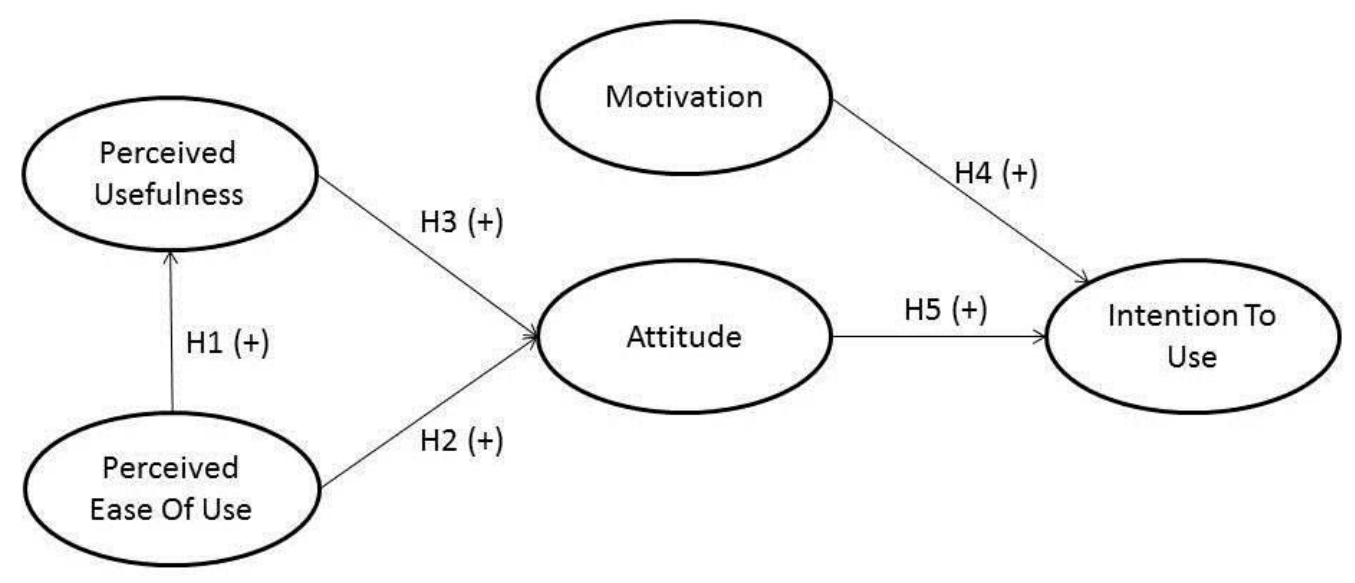

Intensi untuk menggunakan suatu sistem atau teknologi dapat timbul atau bekerja pada seseorang apabila, persepsi kemudahan penggunaan dan persepsi manfaat berujung positif kemudian diikuti oleh sikap yang positif pula. Pernyataan ini didukung oleh pendapat Davis et al: Davis menjelaskan bahwa intensi untuk menggunakan teknologi bisa dijelaskan dalam dua cara, salah satu nya adalah saat persepsi manfaat dan persepsi kemudahan penggunaan berujung positif diikuti oleh sikap yang positif pula.

Peneliti melakukan sebuah pengembangan terhadap model penelitian dengan menambahkan motivasi sabagai variabel independen terhadap intensi untuk menggunakan sebagai variabel dependen. salah satu faktor yang mempengaruhi intensi untuk menggunakan adalah motivasi sebagaimana diasumsikan oleh Ajzen yaitu: Intentions are assumed to capture the motivational factors that influence to behavior. Yang artinya adalah, intensi diasumsikan menangkap faktor motivasi yang mempengaruhi perilaku.

\section{Latar Belakang Teori}

\section{Intensi Untuk menggunakan}

Intensi merupakan sesuatu yang ada pada setiap orang, dengan intensi seseorang akan dapat mempunyai ketertarikan terhadap suatu hal atau objek. Maka dari itu penting untuk mengetahui intensi yang ada pada diri individu, karena dengan mengetahui hal tersebut didapat akan menimbulkan perilaku yang positif. Intensi didefinisikan dalam buku Mowen dan Minor, "Behavioral intention adalah keinginan konsumen untuk berperilaku menurut cara tertentu dalam rangka memiliki, membuang, dan menggunakan produk atau jasa".

\section{Sikap}

Sikap adalah cerminan saat kita berperilaku, sikap yang berujung positif akan berdampak pada perilaku yang positif, sedangkan sikap yang negatif akan mencerminkan perilaku yang negatif pula. Jadi sebelum seorang berperilaku terlebih dahulu dipengaruhi oleh sikap yang positif atau negatif, yang dimana sikap terbentuk dari respon dan objek 
tertentu. Sikap didefinisikan dalam buku Russell H. Fazio, "Sikap (attitude) sebagai evaluasi secara menyeluruh yang dilakukan seseorang atas suatu konsep".

\section{Motivasi}

Salah satu kunci atau faktor yang mendorong intensi seseorang dalam menggunakan sistem adalah motivasi. Dorongan untuk dapat melakukan perilaku tertentu dapat terjadi saat individu memiliki tujuan dan harapan yang spesifik. Menurut Ernest hilgard, Richard Atkinson dan Rita Atkinson, "Motivasi (motivation) adalah keadaan yang diaktivasi atau di gerakan dimana seseorang mengarahkan perilaku berdasarkan tujuan".

\section{Persepsi Manfaat}

Sebelum seseorang mempunyai intensi untuk menggunakan, individu akan melihat manfaat apa yang akan diberikan oleh sistem tersebut. Jika manfaat yang diberikan berdampak baik maka manfaat tersebut akan berujung positif, dan sebaliknya apabila tidak berdampak apapun maka manfaat akan berujung negatif. Persepsi manfaat didefinisikan menurut Davis," Persepsi manfaat adalah sejauh mana seseorang percaya bahwa menggunakan sistem tertentu akan meningkatkan kinerja pekerjaan nya".

\section{Persepsi Kemudahan Penggunaan}

Sebelum seseorang mempunyai intensi untuk menggunakan, individu akan mempertimbangkan dan mencari tahu semudah apa sistem tersebut bisa di operasikan/digunakan, dari segi fitur sampai spesifikasinya yang bertujuan untuk dapat membebaskan pengguna dari beban fisik dan mental. Persepsi kemudahaan penggunaan didefinisikan di dalam buku Pour," Yang apabila diterjemahkan menjadi, Persepsi kemudahan penggunaan didefinisikan sebagai sejauh mana seseorang percaya bahwa menggunakan sistem tertentu akan bebas dari upaya".

\section{Hipotesis}

Berdasarkan uraian teoretik di atas, maka peneliti membuat hipotesis mengenai intensi mahasiswa untuk menggunakan tablet sebagai berikut:

1. H-1: Ada pengaruh positif persepsi kemudahan penggunaan terhadap persepsi manfaat.

2. H-2: Ada pengaruh positif persepsi kemudahan penggunaan terhadap sikap.

3. H-3: Ada pengaruh positif persepsi manfaat terhadap sikap.

4. H-4: Ada pengaruh positif sikap terhadap intensi menggunakan.

5. H-5: Ada pengaruh positif motivasi terhadap intensi menggunakan.

\section{METODE PENELITIAN}

Jenis penelitian yang akan digunakan adalah kuantitatif. Metode kuantitatif ditujukan untuk meneliti pada populasi atau sampel tertentu. Pengumpulan data menggunakan instrumen penelitian. Analisis data bersifat kuantitatif atau statistik dengan tujuan untuk menguji hipotesis. Kemudian diperkuat oleh pendapat Sugiyono, "metode ini disebut 
metode kuantitatif karena data penelitian berupa angka-angka dan analisis menggunakan statistik".

\section{Partisipan}

Partisipan dalam penelitian ini adalah mahasiswa yang tersebar di DKI Jakarta yang menggunakan gadget (Smartphone, Tablet, Phablet). Karakteristik partisipan penelitian ini dikhususkan untuk mereka yang sudah menggunakan gadget dengan hasil positif atau negatif. Dalam pilot study peneliti menyebarkan kuisioner ke 50 mahasiswa yang ada di DKI Jakarta, dan sebanyak 202 mahasiswa untuk proses final.

\section{Pengembangan Instrumen}

Dalam penelitian ini data yang digunakan adalah data primer. Data primer menurut Malhotra adalah data yang dibuat oleh peniliti untuk untuk maksud khusus menyelesaikan masalah riset.

Data primer peneliti dapatkan dari pengisian kuesioner oleh responden. Kuesioner berisi pertanyaan-pertanyan seputar variabel yang ingin diteliti yaitu pengaruh motivasi, sikap, persepsi manfaat dan persepsi kemudahan penggunaan terhadap intensi menggunakan.

Penelitian ini menggunakan skala ukur yaitu skala Likert (Likert scale). Peneliti menyediakan enam kemungkinan pilihan jawaban yaitu: STS, TS, SDTS, SDS, S, SS. Hal tersebut dapat dilihat dalam tabel berikut:

Tabel 1.

Skala penilaian instrumen

\begin{tabular}{|l|l|l|}
\hline No & Alternatif Jawaban & Skor \\
\hline 1 & Sangat Tidak Setuju (STS) & 1 \\
\hline 2 & Tidak Setuju (TS) & 2 \\
\hline 3 & Sedikit Tidak Setuju (SDTS) & 3 \\
\hline 4 & Sedikit Setuju (SDS) & 4 \\
\hline 5 & Setuju (S) & 5 \\
\hline 6 & Sangat Setuju (SS) & 6 \\
\hline
\end{tabular}

Sumber: Data diolah oleh penulis (2016)

Alasan menggunakan skala likert dengan 6 skor, dikutip dari infosurv.com mengenai alasan menggunakan skala likert dengan 6 point yaitu:

1. Mereka lebih memilih untuk memiliki jumlah skala yang banyak, untuk membuat komitmen responden dalam mengisi jawaban dengan akhir positif atau negatif dari skala tersebut, karena para peneliti ini tidak menyukai jawaban netral atau ambivalen.

2. Mereka juga berpendapat bahwa jawaban netral itu jarang ada disetiap kasus, karena hanya mereka yang memiliki pengalaman positif dan negatif, opini nya akan bisa berpartisipasi dalam studi penelitian. 
Berdasarkan referensi yang ada di atas, dapat disimpulkan alasan menggunakan skala likert dengan 6 skor adalah untuk menghindari jawaban netral, karena hanya mereka yang memiliki pengalaman positif dan negatif, opini nya akan bisa berpartisipasi dalam studi penelitian.

\section{HASIL DAN PEMBAHASAN}

\section{Exploratory Factor Analysis}

Exploratory factor analysis merupakan analisis untuk mengelompokkan item atau variabel berdasarkan kemiripannya. Kemiripan tersebut ditunjukkan dengan nilai korelasi yang tinggi. Item-item yang memiliki korelasi yang tinggi akan membentuk satu faktor atau dimensi.

Pada penelitian ini uji EFA dan uji reliabilitas diukur dengan menggunakan factor analysis. Pengolahan factor analysis menggunakan SPSS versi 23. Dihitung dengan dimension reduction-factor. Pada extraction, maximum iterations for convergence sebesar 40, Pada rotation menggunakan direct oblimin. Serta pada option menggunakan Absolute value below sebesar 0,4 .

Suatu kuisioner dikatakan reliabel atau handal jika jawaban seseorang terhadap pertanyaan adalah konsisten atau stabil dari waktu ke waktu. reliabilitas dilakukan terhadap seluruh butir pertanyaan dengan menggunakan metode Cronbach's Alpha jika nilai Alpha > 0,60 maka reliabel.

\section{Variabel Persepsi Kemudahan Penggunaan}

Tabel 2.

Pernyataan dan Factor Loading persepsi kemudahan penggunaan

\begin{tabular}{|c|c|c|c|c|}
\hline \multirow[t]{2}{*}{ Nama } & \multirow[t]{2}{*}{ Pernyataan } & \multicolumn{3}{|c|}{ Factor } \\
\hline & & 1 & 2 & 3 \\
\hline \multicolumn{5}{|c|}{ Dimensi: Mudah digunakan } \\
\hline PE0U1 & $\begin{array}{l}\text { Saya akan menggunakan tablet, karena } \\
\text { tablet mudah untuk digunakan }\end{array}$ & ,857 & & \\
\hline PEOU3 & $\begin{array}{l}\text { Saya akan menggunakan tablet, karena } \\
\text { tablet mudah untuk dipelajari }\end{array}$ & 688 & & \\
\hline PEOU7 & $\begin{array}{l}\text { Saya akan menggunakan tablet, karena } \\
\text { tidak sulit untuk dipelajari }\end{array}$ & 650 & & \\
\hline PEOU8 & $\begin{array}{l}\text { Saya akan menggunakan tablet, karena } \\
\text { fungsi nya sangat jelas untuk dimengerti. }\end{array}$ & 639 & & \\
\hline PEOU2 & $\begin{array}{l}\text { Saya akan menggunakan tablet, karena } \\
\text { tablet mudah dioperasikan }\end{array}$ & ,587 & & \\
\hline \multicolumn{2}{|c|}{ Cronbach's Alpha } & \multicolumn{3}{|l|}{,780 } \\
\hline
\end{tabular}




\begin{tabular}{|c|c|c|c|c|}
\hline PEOU10 & $\begin{array}{l}\text { Saya tidak akan menggunakan tablet, } \\
\text { karena tablet tidak mudah dioperasikan }\end{array}$ & & 873 & \\
\hline PEOU13 & $\begin{array}{l}\text { Saya tidak akan menggunakan tablet, } \\
\text { karena fungsi nya sangat tidak jelas untuk } \\
\text { dimengerti. }\end{array}$ & & 823 & \\
\hline PEOU9 & $\begin{array}{l}\text { Saya tidak akan menggunakan tablet, } \\
\text { karena tablet sulit untuk digunakan }\end{array}$ & & ,769 & \\
\hline PEOU12 & $\begin{array}{l}\text { Saya tidak akan menggunakan tablet, } \\
\text { karena tidak sulit untuk dipelajari }\end{array}$ & & 659 & \\
\hline \multicolumn{2}{|c|}{ Cronbach's Alpha } & \multicolumn{3}{|l|}{,805 } \\
\hline \multicolumn{5}{|c|}{ Dimensi: Mudah Dimengerti } \\
\hline PEOU5 & $\begin{array}{l}\text { Dengan menggunakan tablet, saya akan } \\
\text { menghemat waktu dalam menyelesaikan } \\
\text { tugas perkuliahan }\end{array}$ & & & ,882 \\
\hline PEOU6 & $\begin{array}{l}\text { Dengan menggunakan tablet, saya akan } \\
\text { menjadi terampil. }\end{array}$ & & & ,792 \\
\hline PEOU4 & $\begin{array}{l}\text { Dengan menggunakan tablet, saya akan } \\
\text { menghemat usaha/tenaga dalam } \\
\text { menyelesaikan tugas perkuliahan }\end{array}$ & & & ,747 \\
\hline \multicolumn{2}{|c|}{ Cronbach's Alpha } & \multicolumn{3}{|l|}{,798 } \\
\hline
\end{tabular}

Sumber: Data diolah olah penulis (2016)

Dari 13 pernyataan kuisioner final, hanya 1 pernyataan yang gugur di variabel persepsi kemudahan penggunaan dan dapat membentuk faktor atau dimensi. Hasil faktor analisis membentuk tiga dimensi yaitu dimensi mudah digunakan, jelas dimengerti dan mudah dimengerti. Nilai cronbach's alpha dari ketiga dimensi menyatakan $>0,60$ yaitu reliabel.

\section{Variabel Persepsi Manfaat}

Tabel 3.

Pernyataan dan Factor Loading persepsi manfaat

\begin{tabular}{|l|l|l|l|l|}
\hline Nama & Pernyataan & \multicolumn{2}{|l|}{ Factor } & \\
\cline { 2 - 5 } & \multicolumn{1}{|l|}{1} & 2 & 3 \\
\hline Dimensi: Membuat Pekerjaan Lebih Mudah & & \\
\hline PU3 & $\begin{array}{l}\text { Dengan menggunakan tablet, saya akan } \\
\text { selalu dapat menangani kesulitan dalam } \\
\text { belajar. }\end{array}$ &, 885 & & \\
\hline PU6 & $\begin{array}{l}\text { Saya akan menggunakan tablet, karena } \\
\text { dapat meningkatkan prestasi belajar. }\end{array}$ &, 865 & & \\
\hline PU7 & $\begin{array}{l}\text { Dengan menggunakan tablet, saya akan } \\
\text { mendapatkan hasil belajar yang optimal. }\end{array}$ &, 804 & & \\
\hline PU5 & $\begin{array}{l}\text { Dengan menggunakan tablet, tugas } \\
\text { perkuliahan akan menjadi lebih efektif }\end{array}$ &, 758 & & \\
\hline
\end{tabular}




\begin{tabular}{|c|c|c|c|c|}
\hline PU4 & $\begin{array}{l}\text { Dengan menggunakan tablet, saya akan } \\
\text { dapat meningkatkan produktivitas belajar. }\end{array}$ & ,717 & & \\
\hline PU2 & $\begin{array}{l}\text { Saya akan menggunakan tablet, karena } \\
\text { dapat membantu kebutuhan saat } \\
\text { menyelesaikan tugas perkuliahan }\end{array}$ & 623 & & \\
\hline \multicolumn{2}{|c|}{ Cronbach's Alpha } & \multicolumn{3}{|l|}{,878 } \\
\hline \multicolumn{5}{|c|}{ Dimensi: Meningkatkan Produktifitas } \\
\hline PU16 & $\begin{array}{l}\text { Saya tidak akan menggunakan tablet, karena } \\
\text { tidak bisa meningkatkan prestasi belajar. }\end{array}$ & & ,867 & \\
\hline PU14 & $\begin{array}{l}\text { Dengan menggunakan tablet, saya tidak } \\
\text { akan bersemangat untuk mengerjakan tugas } \\
\text { perkuliahan. }\end{array}$ & & ,864 & \\
\hline PU15 & $\begin{array}{l}\text { Dengan menggunakan tablet, tugas } \\
\text { perkuliahan tidak akan menjadi lebih efektif }\end{array}$ & & ,863 & \\
\hline PU17 & $\begin{array}{l}\text { Dengan menggunakan tablet, saya tidak } \\
\text { akan mendapatkan hasil belajar yang } \\
\text { optimal. }\end{array}$ & & ,826 & \\
\hline PU12 & $\begin{array}{l}\text { Dengan menggunakan tablet, saya tidak } \\
\text { akan bisa meningkatkan produktivitas } \\
\text { belajar. }\end{array}$ & & ,577 & \\
\hline \multicolumn{2}{|c|}{ Cronbach's Alpha } & \multicolumn{3}{|l|}{881} \\
\hline \multicolumn{5}{|c|}{ Dimensi: Memungkinkan Individu Bekerja Lebih Cepat } \\
\hline PU8 & $\begin{array}{l}\text { Dengan menggunakan tablet, saya tidak } \\
\text { akan bisa menyelesaikan tugas-tugas } \\
\text { perkuliahan lebih cepat. }\end{array}$ & & & ,952 \\
\hline PU9 & $\begin{array}{l}\text { Dengan menggunakan tablet, saya tidak } \\
\text { akan bisa membuat tugas perkuliahan } \\
\text { menjadi lebih efisien. }\end{array}$ & & & ,898 \\
\hline \multicolumn{2}{|c|}{ Cronbach's Alpha } & \multicolumn{3}{|l|}{886} \\
\hline
\end{tabular}

Sumber: Data diolah olah penulis (2016)

Dari 17 pernyataan kuisioner final, terdapat 4 pernyataan yang gugur di variabel persepsi manfaat dan dapat membentuk faktor atau dimensi. Hasil faktor analisis membentuk tiga dimensi yaitu dimensi Membuat Pekerjaan Lebih Mudah, Meningkatkan Produktifitas dan Memungkinkan Individu Bekerja Lebih Cepat. Nilai cronbach's alpha dari ketiga dimensi menyatakan $>0,60$ yaitu reliabel. 


\section{Variabel Sikap}

Tabel 4.

Pernyataan dan Factor Loading sikap

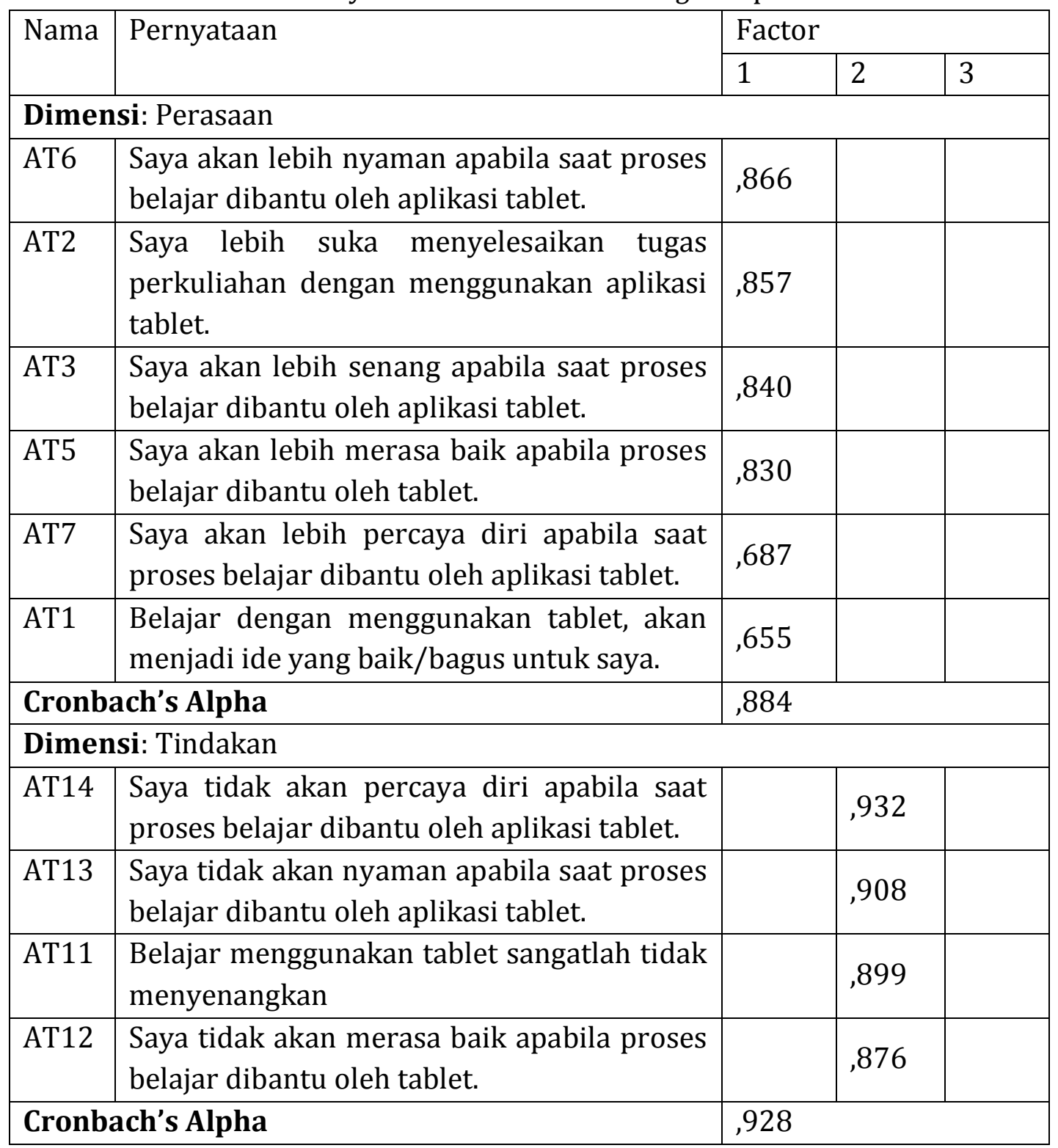

Sumber: Data diolah olah penulis (2016)

Dari 14 pernyataan kuisioner final, terdapat 4 pernyataan yang gugur di variabel sikap dan dapat membentuk faktor atau dimensi. Hasil faktor analisis membentuk dua dimensi yaitu dimensi perasaan dan tindakan. Nilai cronbach's alpha dari kedua dimensi menyatakan > 0,60 yaitu reliabel. 


\section{Variabel Motivasi}

Tabel 5.

Pernyataan dan Factor Loading motivasi

\begin{tabular}{|c|c|c|c|c|c|}
\hline \multirow[t]{2}{*}{ Nama } & \multirow[t]{2}{*}{ Pernyataan } & \multicolumn{4}{|c|}{ Factor } \\
\hline & & 1 & 2 & 3 & 4 \\
\hline \multicolumn{6}{|c|}{ Dimensi: Tingkah Laku } \\
\hline MT13 & $\begin{array}{l}\text { Dengan menggunakan tablet, saya tidak } \\
\text { akan bisa menikmati berbagai aplikasi } \\
\text { yang bisa dimanfaatkan saat belajar. }\end{array}$ & ,851 & & & \\
\hline MT15 & $\begin{array}{l}\text { Dengan menggunakan tablet, saya tidak } \\
\text { akan bisa menghemat waktu dalam } \\
\text { mengerjakan tugas perkuliahan. }\end{array}$ & ,841 & & & \\
\hline MT14 & $\begin{array}{l}\text { Dengan menggunakan tablet, saya tidak } \\
\text { akan bisa memperluas pengetahuan } \\
\text { dalam penggunaan teknologi }\end{array}$ & ,800 & & & \\
\hline MT12 & $\begin{array}{l}\text { Dengan menggunakan tablet, saya tidak } \\
\text { akan bisa meningkatkan keterampilan } \\
\text { dalam menggunakan teknologi }\end{array}$ & 645 & & & \\
\hline MT10 & $\begin{array}{l}\text { Dengan menggunakan tablet, saya tidak } \\
\text { dapat mencoba hal-hal baru }\end{array}$ & ,623 & & & \\
\hline \multicolumn{2}{|c|}{ Cronbach's Alpha } & \multicolumn{4}{|l|}{, 874} \\
\hline \multicolumn{6}{|c|}{ Dimensi: Hiburan } \\
\hline MT7 & $\begin{array}{l}\text { Dengan menggunakan tablet, saya akan } \\
\text { memiliki berbagai cara berkomunikasi } \\
\text { dengan orang lain (misalnya, line, bbm, } \\
\text { whatssap) }\end{array}$ & & 964 & & \\
\hline MT8 & $\begin{array}{l}\text { Dengan menggunakan tablet, saya akan } \\
\text { dapat berbagi peristiwa dengan teman- } \\
\text { teman/keluarga (misalnya, twitter, } \\
\text { facebook, path, instagram) }\end{array}$ & & ,939 & & \\
\hline MT6 & $\begin{array}{l}\text { Dengan menggunakan tablet, saya akan } \\
\text { selalu dapat mengorganisir (misalnya, } \\
\text { memeriksa, email, jadwal, rencana) }\end{array}$ & & 636 & & \\
\hline \multicolumn{2}{|c|}{ Cronbach's Alpha } & \multicolumn{4}{|l|}{,844 } \\
\hline \multicolumn{6}{|c|}{ Dimensi: Tujuan Daripada Tingkah Laku } \\
\hline MT5 & $\begin{array}{l}\text { Dengan menggunakan tablet, saya akan } \\
\text { dapat memperluas pengetahuan dalam } \\
\text { penggunaan teknologi }\end{array}$ & & &,- 732 & \\
\hline MT3 & $\begin{array}{l}\text { Dengan menggunakan tablet, saya akan } \\
\text { dapat meningkatkan keterampilan } \\
\text { dalam menggunakan teknologi }\end{array}$ & & &,- 692 & \\
\hline
\end{tabular}




\begin{tabular}{|c|c|c|c|c|}
\hline MT4 & $\begin{array}{l}\text { Dengan menggunakan tablet, saya akan } \\
\text { dapat menikmati berbagai aplikasi yang } \\
\text { bisa dimanfaatkan saat belajar. }\end{array}$ & &,- 676 & \\
\hline MT9 & $\begin{array}{l}\text { Dengan menggunakan tablet, saya akan } \\
\text { dapat berbagi pengetahuan (seputar } \\
\text { aplikasi tablet) ke teman- } \\
\text { teman/keluarga. }\end{array}$ & &,- 595 & \\
\hline \multicolumn{2}{|c|}{ Cronbach's Alpha } & \multicolumn{3}{|l|}{,764 } \\
\hline \multicolumn{5}{|c|}{ Dimensi: Menemukan Hal-Hal Baru } \\
\hline MT2 & $\begin{array}{l}\text { Dengan menggunakan tablet, saya akan } \\
\text { menemukan hal-hal baru }\end{array}$ & & & ,896 \\
\hline MT1 & $\begin{array}{l}\text { Dengan menggunakan tablet, saya } \\
\text { dapat mencoba hal-hal baru }\end{array}$ & & & 804 \\
\hline \multicolumn{2}{|c|}{ Cronbach's Alpha } & \multicolumn{3}{|l|}{833} \\
\hline
\end{tabular}

Sumber: Data diolah olah penulis (2016)

Dari 17 pernyataan kuisioner final, terdapat 3 pernyataan yang gugur di variabel motivasi dan dapat membentuk faktor atau dimensi. Hasil faktor analisis membentuk empat dimensi yaitu dimensi tingkah laku, hiburan, Tujuan Daripada Tingkah Laku dan menemukan hal-hal baru. Nilai cronbach's alpha dari keempat dimensi menyatakan reliabel.

\section{Variabel Intensi Menggunakan}

Tabel 6.

Pernyataan dan Factor Loading intensi menggunakan

\begin{tabular}{|c|c|c|c|}
\hline \multirow[t]{2}{*}{ Nama } & \multirow[t]{2}{*}{ Pernyataan } & \multicolumn{2}{|c|}{ Factor } \\
\hline & & 1 & 2 \\
\hline \multicolumn{4}{|c|}{ Dimensi: Ambisi } \\
\hline $\mathrm{I} 4$ & $\begin{array}{lrr}\text { Saya berniat } & \text { menggunakan } & \text { tablet untuk } \\
\text { membantu } & \text { menyelesaikan } & \text { tugas-tugas } \\
\text { perkuliahan. } & & \end{array}$ & ,946 & \\
\hline I3 & $\begin{array}{l}\text { Saya berniat untuk menggunakan aplikasi- } \\
\text { aplikasi yang terdapat pada tablet. }\end{array}$ & , 859 & \\
\hline I5 & $\begin{array}{l}\text { Saya berniat untuk menggunakan tablet baik } \\
\text { dalam } \\
\text { proses belajar maupun di luar belajar. }\end{array}$ & ,853 & \\
\hline $\mathrm{I} 2$ & $\begin{array}{l}\text { Saya berniat menggunakan tablet untuk proses } \\
\text { belajar dalam beberapa bulan kedepan. }\end{array}$ & 838 & \\
\hline I1 & $\begin{array}{l}\text { Saya berniat untuk menggunakan Tablet dalam } \\
\text { beberapa bulan kedepan. }\end{array}$ & ,725 & \\
\hline \multicolumn{2}{|c|}{ Cronbach's Alpha } & \multicolumn{2}{|l|}{905} \\
\hline
\end{tabular}




\begin{tabular}{|l|l|l|l|}
\hline \multicolumn{2}{|l|}{ Dimensi: Tujuan } &, 872 \\
\hline I7 & $\begin{array}{l}\text { Saya tidak berniat untuk menggunakan aplikasi- } \\
\text { aplikasi yang terdapat pada tablet. }\end{array}$ &, 860 \\
\hline I6 & $\begin{array}{l}\text { Saya tidak berniat menggunakan tablet untuk } \\
\text { proses belajar di beberapa bulan kedepan. }\end{array}$ &, 659 \\
\hline I8 & $\begin{array}{l}\text { Saya tidak berniat menggunakan tablet untuk } \\
\text { membantu menyelesaikan tugas-tugas } \\
\text { perkuliahan. }\end{array}$ &, 563 \\
\hline I9 & $\begin{array}{l}\text { Saya tiak berniat untuk menggunakan tablet baik } \\
\text { dalam belajar maupun di luar belajar. }\end{array}$ &, 766 & \\
\hline Cronbach's Alpha
\end{tabular}

Sumber: Data diolah olah penulis (2016)

Dari 9 pernyataan kuisioner final, tidak ada pernyataan yang gugur di variabel intensi menggunakan dan dapat membentuk faktor atau dimensi. Hasil faktor analisis membentuk dua dimensi yaitu dimensi kecenderungan merencanakan dan kecenderungan berharap. Nilai cronbach's alpha dari kedua dimensi menyatakan $>0,60$ yaitu reliabel.

\section{Confirmatory Factor Analysis}

Dalam penelitian ini peneliti menggunakan teknik Structural Equation Modeling (SEM) dengan menggunakan software AMOS 22. Permodelan persamaan struktural (Structural Equation Modeling) biasa disingkat dengan SEM menurut Sugiyono dapat dideskripsikan sebagai suatu analisis yang menggabungkan pendekatan analisis faktor (factor analysis), model structural (structural model), dan analisis jalur (path analysis).

\section{Model Fit Keseluruhan}

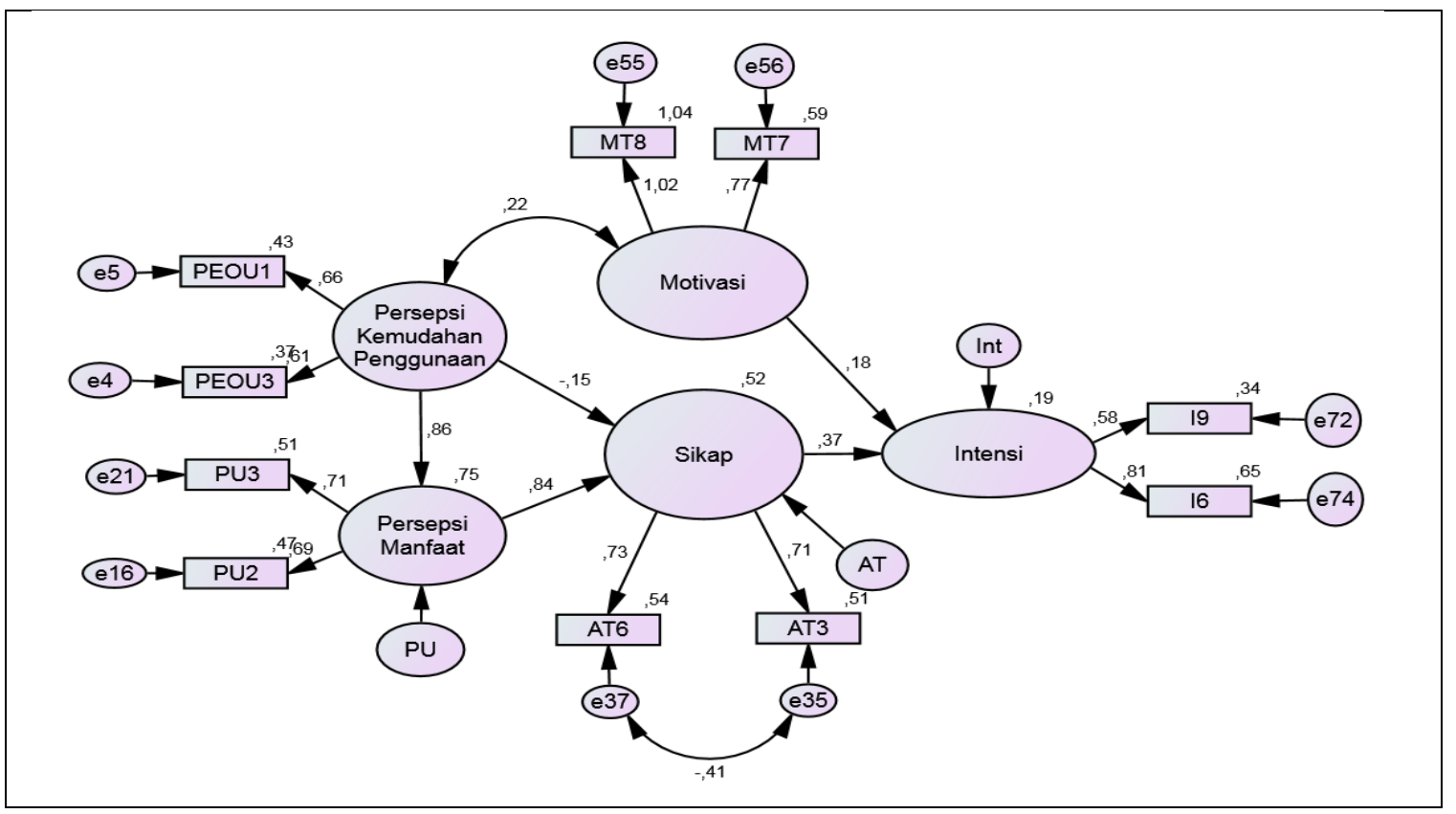

Sumber: Data diolah oleh penulis (2016) 


\begin{tabular}{|l|l|l|l|}
\hline Indeks & Cut Off Value & Hasil & Evaluasi Model \\
\hline P & $\geq 0.05$ &, 554 & Fitted \\
\hline CMIN/DF & $\leq 2.00$ &, 941 & Fitted \\
\hline TLI & $\geq 0.95$ & 1,005 & Fitted \\
\hline CFI & $\geq 0.95$ & 1,000 & Fitted \\
\hline RMSEA & $\leq 0.08$ &, 000 & Fitted \\
\hline
\end{tabular}

Hasil dari pengujian fit model ini P sebesar ,554, CMIN/DF sebesar ,941, RMSEA sebesar 0.000, TLI sebesar 1,005 dan CFI sebesar 1,000. Berdasarkan hasil dari lima alat ukur (P,CMIN/DF,TLI, CFI, dan RMSEA) semua menunjukkan angka yang baik sesuai kriteria indeks, yang mengindikasikan bahwa model sudah fit dengan data yang ada.

\section{Pernyataan Indikator Fit Model}

\begin{tabular}{|c|c|}
\hline Item & Pernyataan Variabel Intensi Menggunakan \\
\hline I5 & $\begin{array}{l}\text { Saya berniat menggunakan tablet baik dalam belajar maupun diluar } \\
\text { belajar }\end{array}$ \\
\hline I9 & $\begin{array}{l}\text { Saya tidak berniat untuk menggunakan aplikasi tablet baik dalam } \\
\text { belajar maupun diluar belajar }\end{array}$ \\
\hline Item & Pernyataan Variabel Motivasi \\
\hline MT7 & $\begin{array}{l}\text { Dengan menggunakan tablet, saya akan memiliki berbagai cara } \\
\text { berkomunikasi dengan orang lain (misal, line, whatssap, bbm) }\end{array}$ \\
\hline MT8 & $\begin{array}{l}\text { Dengan menggunakan tablet saya akan dapat berbagi peristiwa } \\
\text { dengan teman-teman/keluarga (misal, path, instagram, facebook, } \\
\text { twitter) }\end{array}$ \\
\hline Item & Pernyataan Variabel Sikap \\
\hline AT3 & $\begin{array}{l}\text { Saya akan merasa lebih senang apabila proses belajar dibantu oleh } \\
\text { aplikasi tablet }\end{array}$ \\
\hline AT6 & $\begin{array}{l}\text { Saya akan merasa lebih nyaman apabila proses belajar dibantu } \\
\text { aplikasi tablet }\end{array}$ \\
\hline Item & Pernyataan Variabel Persepsi Manfaat \\
\hline PU2 & $\begin{array}{l}\text { Saya akan menggunakan tablet, karena dapat membantu kebutuhan } \\
\text { saat menyelesaikan tugas perkuliahan }\end{array}$ \\
\hline PU3 & $\begin{array}{l}\text { Dengan menggunakan tablet saya akan selalu dapat menangani } \\
\text { kesulitan dalam belajar }\end{array}$ \\
\hline Item & Pernyataan Variabel Persepsi Kemudahan Penggunaan \\
\hline PEOU4 & $\begin{array}{l}\text { Dengan menggunakan tablet, saya akan menghemat usaha/tenaga } \\
\text { dalam menyelesaikan tugas perkuliahan }\end{array}$ \\
\hline PEOU5 & $\begin{array}{l}\text { Dengan menggunakan tablet, saya akan menghemat waktu dalam } \\
\text { menyelesaikan tugas perkuliahan }\end{array}$ \\
\hline
\end{tabular}

Sumber: Data diolah oleh penulis (2016) 


\begin{tabular}{|c|c|c|c|c|c|c|}
\hline 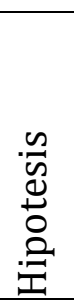 & 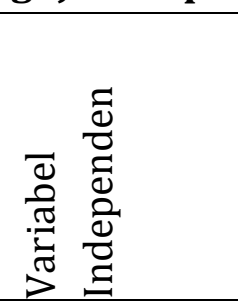 & & 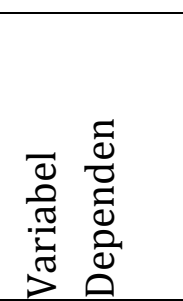 & 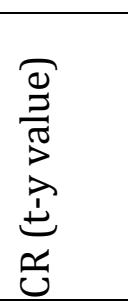 & $\begin{array}{l}\stackrel{0}{3} \\
\frac{\pi}{\pi} \\
\stackrel{1}{2}\end{array}$ & 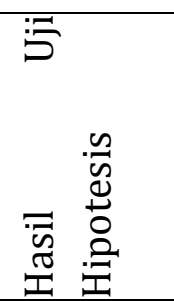 \\
\hline $\mathrm{H} 1$ & $\begin{array}{l}\text { persepsi } \\
\text { kemudahan } \\
\text { penggunaan }\end{array}$ & $\rightarrow$ & $\begin{array}{l}\text { Persepsi } \\
\text { Manfaat }\end{array}$ & 5,533 & $* * *$ & Diterima \\
\hline $\mathrm{H} 2$ & $\begin{array}{l}\text { persepsi } \\
\text { kemudahan } \\
\text { penggunaan }\end{array}$ & $\rightarrow$ & Sikap & -371 & 711 & Ditolak \\
\hline H3 & $\begin{array}{l}\text { Persepsi } \\
\text { Manfaat }\end{array}$ & $\rightarrow$ & Sikap & 1,965 & 0,049 & Diterima \\
\hline H4 & Motivasi & $\rightarrow$ & Intensi & 2,070 & 0,038 & Diterima \\
\hline H5 & Sikap & $\rightarrow$ & Intensi & 2,142 & 0,032 & Diterima \\
\hline
\end{tabular}

Sumber: Data diolah oleh peneliti (2016)

\section{SIMPULAN}

\section{Simpulan}

Penelitian ini bertujuan untuk menguji faktor-faktor yang mempengaruhi intensi menggunakan tablet pada mahasiswa meliputi faktor persepsi kemudahan penggunaan, persepsi manfaat, sikap dan motivasi. Sampel yang digunakan dalam penelitian ini sebanyak 202 responden. kuesioner disebarkan ke mahasiswa dibeberapa universitas di Jakarta. Untuk pengolahan data peneliti menggunakan SPSS untuk exploratory factor analysis dan AMOS untuk confirmatory factor analysis. Setelah peneliti melakukan analisis mengenai pengaruh persepsi kemudahan penggunaan, persepsi manfaat, sikap dan motivasi terhadap intensi mahasiswa untuk menggunakan tablet, maka dapat ditarik kesimpulan sebagai berikut:

1. H1 menunjukkan bahwa variabel persepsi kemudahan penggunaan memiliki nilai critical ratio (CR) sebesar 5.533, ini berarti lebih dari 1.96 , maka $\mathrm{H}_{1}$ yang menyatakan bahwa persepsi kemudahan penggunaan positif dan signifikan terhadap persepsi manfaat diterima. Dengan demikian ternyata mahasiswa lebih mengutakamakan kemudahan dalam peggunaan yang mempengaruhi persepsi mereka terhadap manfaat teknologi tersebut.

2. $\mathrm{H}_{2}$ menyatakan bahwa ada pengaruh positif dan signifikan persepsi kemudahan penggunaan terhadap sikap ditolak dengan nilai critical ratio -,371 > 1.96 dan nilai P sebesar $0.711 \leq 0.05$. Dengan demikian perspsi kemudahan penggunaan yang dirasakan mahasiswa di Jakarta tidak berpengaruh terhadap sikap terhadap penggunaan teknologi tersebut. 
3. $\mathrm{H}_{3}$ memiliki critical ratio (CR) sebesar $1,965>1.96$ dan Skor P sebesar 0,049 $\leq$ 0.05 . Hal itu menunjukkan bahwa hipotesis ketiga diterima yang berarti persepsi manfaat memiliki pengaruh positif dan signifikan terhadap sikap. Semakin bagus manfaat yang diberikan oleh sebuah sistem teknologi ternyata akan berdampak terhadap sikap mahasiswa di Jakarta.

4. Variabel motivasi memiliki nilai P 0,038 dan critical ratio sebesar 2,070 > 1.96. hal ini menunjukkan motivasi berpengaruh positif dan signifikan terhadap intensi menggunakan, sehingga $\mathrm{H}_{4}$ diterima

5. Dan yang terakhir yaitu terdapat pengruh positif dan signifikan sikap terhadap intensi menggunakan dengan nilai P 0,032 < 0,05 dan nilai critical ratio sebesar 2,142 > 1,96 yang menyatakan bahwa $\mathrm{H}_{5}$ diterima.

\section{Saran}

Berdasarkan implikasi yang sudah dikemukakan, maka beberapa saran dari hasil penelitian yang diperuntukan untuk pembaca dan perusahaan yang memproduksi produk teknologi gadget ini diantaranya adalah

1. Perlu adanya evaluasi terhadap perusahaan yang memproduksi Tablet, untuk lebih memperhatikan kemudahaan dari penggunaan Tablet tersebut seperti fiturfitur yang dapat menunjang kebutuhan agar si pemakai bisa lebih jelas mengerti pengolahan daripada teknologi tersebut..

2. Perlu adanya lebih banyak pengayaan manfaat terhadap Tablet, agar pengguna dapat menunjang kebutuhan sehari-hari menjadi lebih produktif dan efisien. Hal tersebut baik untuk mempengaruhi sikap daripada pengguna.

\section{DAFTAR PUSTAKA}

Efi Sapriyanti, Pengguna internet di Indonesia mayoritas usia 18-25 tahun, Bulet.in, diakses tanggal 29 februari 2016, pukul 17:57 WIB.

Marie Gunawan ,Seiring Meningkatnya Pembelian Tablet Enterprise, Apple Resmikan iPad Pro, http://www.teknoup.com diakses tanggal 27 februari 2016, pukul 17:23 WIB.

Khancantanee, Suwanno, dan Jarernvongrayab, Effects of Attitude toward Using, Perceived Usefulness, Perceived Ease of Use and Perceived Compatibility on Intention to Use E-Marketing, Journal of Management Research, 2014, Vol. 6, No. 3.

O'regan dan Chan, Smartphone adoption amongst chinese youth during leisure-based tourism: Challenges and opportunities, Journal of China Tourism Research, 00: 1-17, 2015.

Kim, Kim, dan Wachter, A study of mobile user engagement (MoEN): Engagement motivations, perceived value, satisfaction, and continued engagement intention. 
Omigie, Zo dan Rho, User acceptanceof mobile broadband in Nigeria, Information and Knowledge Management, Vol.5, No.7, 2015

Raman dan Krishnasamy, Skype in the English language, International Journal of Humanities and Social Science Research, Volume 1; Issue 2; December 2015; Page No. 38-42

Gayar, Moran, dan Hawkes, Students' Acceptance of Tablet PCs and Implications for Educational Institutions, Institutions. Educational Technology \& Society, 14 (2), 5870 .

Kanchantanee, Suwanno, dan Jarenvongrayeb, loc.cit. hal.4

Praveena dan Thomas, Continuance to use facebook: A study of Perceived enjoyment and TAM, Bonfring International Journal of Industrial Engineering and Management Science, Vol. 4, No. 1, February 2014

Khanh dan Gim, Factors influencing mobile-learning adoption intention: an empirical investigation in high education, Journal of Social Sciences 10 (2): 51-62, 2014

Nawaz dan Thelijjagoda, Sri Lankan Citizens' Use Behaviour towards E-Government Services, European Journal of Business and Management, Vol.7, No.8, 2015

Juniwati, Influence of perceived usefulness, ease of use, risk on attitude and intention to shop online, European Journal of Business and Management, Vol.6, No.27, 2014

Praveena dan Thomas, Loc.cit. hal.6

Kim, A study on adoption factors of korean smartphone users: a focus on TAM (technology acceptence model) and UTAUT (unified theory of acceptence and use of technology), Advanced Science and Technology Letters Vol.57 (Business 2014), pp. 27-30

Park, An analysis the technology acceptence model in understanding university student' behavioral intention to use e-learning, Educational Technology \& Society, 12 (3), 150-162.

Management association, Information research, Loc.cit

Mahmood, loc.cit, h 66.

Rathore dan Panwar, Capturing, analyzing, and managing word-of-mouth in the digital marketplace, (USA: IGI Global, 2014), h 217.

Jhon C. Mowen dan Michael Minor, perilaku konsumen edisi 5, (Jakarta:Erlangga), 2002, h 322.

J. Paul Peter dan Jerry C. Olson, Loc.cit, h 130.

Jhon C. Mowen dan Michael Minor, loc.cit. h 205. 
Hung, Wong, Cho, Ubiquitous commerce for creating the personalized marketplace, (United State: IGI Global, 2009), h 59.

Bahri dan Zamzam, Model penelitian kuantitatif berbasis SEM-AMOS, (YogyakartaDeepublish, 2014), h 5.

Malhotra, Riset Pemasaran, (Jakarta: PT. Indeks.2009),

Chris Gwinner, infosurv paper 5 point likert vs 6 point likert, www.infosurv.com, diakses tanggal 15 april 2016, pukul 15:28 WIB.

Sugiyono, Statistika untuk Penelitian (Bandung: Alfabeta, 2013), p.323 